\title{
On the immature stages and natural history of Gonioterma exquisita Duckworth (Lepidoptera, Elachistidae, Stenomatinae)
}

\author{
Rosevaldo Pessoa-Queiroz ${ }^{1} \&$ Ivone Rezende Diniz ${ }^{2}$
}

'Pós-graduação em Ecologia, Instituto de Ciências Biológicas, Universidade de Brasília, ICC sul, Térreo, Campus Universitário Darcy Ribeiro, Asa Norte, 70919-970, Brasília-DF, Brasil. rosevaldo.queiroz@gmail.com

${ }^{2}$ Departamento de Zoologia, Instituto de Ciências Biológicas, Universidade de Brasília, ICC sul, Térreo, Sala AT-116, Campus Universitário Darcy Ribeiro, Asa Norte, 70910-900, Brasília-DF, Brasil. irdiniz@unb.br

\begin{abstract}
On the immature stages and natural history of Gonioterma exquisita Duckworth (Lepidoptera, Elachistidae, Stenomatinae). In the present work the natural history and immature stages of Gonioterma exquisita Duckworth, 1964 of the Brazilian cerrado region are described. The caterpillars are external folivorous feeders and present a diet restricted to pubescent-leaved host plants of the genus Byrsonima Rich. (Malpighiaceae). They are solitary caterpillars and they build a hard individual shelter that looks like a planorbid shell, made from silk and frass, covered with trichomes and silk, where they develop until the last larval instar on the host plant, and remain inside it until the adult emergence on herbaceous stratum. The larval development presented eight instars. Egg, larval head capsules, instar duration, pupa, shelter, and behavior are also described. Diapause is mentioned for the first time in this species.
\end{abstract}

KEYWORDS. Brazil, Byrsonima, Cerrado, restricted diet.

RESUMO. Sobre estágios imaturos e história natural de Gonioterma exquisita Duckworth (Lepidoptera, Elachistidae, Stenomatinae). Este trabalho apresenta a história natural e descreve os imaturos de Gonioterma exquisita Duckworth, 1964 em uma região do cerrado brasileiro. As larvas são folívoras externas e apresentam dieta restrita a plantas de folhas pubescentes do gênero Byrsonima Rich. (Malpighiaceae). São larvas solitárias que constróem um abrigo bastante rígido com formato de uma concha de moluscos planorbídeos. Neste abrigo, feito de seda e fezes e coberto de seda e tricomas, as larvas desenvolvem-se até o instar final na planta hospedeira e permanecem dentro dele até a emergência do adulto, já no estrato herbáceo. O desenvolvimento larval caracteriza-se por apresentar oito ínstares. Ovo, larvas, cápsulas cefálicas, duração dos ínstares e do período de pupa, abrigos e comportamento são também descritos. Pela primeira vez é mencionada a diapausa nesta espécie.

PALAVRAS-CHAVE. Brasil, Byrsonima, Cerrado, dieta restrita.

The Elachistidae comprises inconspicuous and small moths, often cryptic in their appearence and behavior. In a published list of lepidopteran caterpillars and their host plants in the Distrito Federal (Brazil) Diniz et al. (2001) reported that Elachistidae is the most speciose family associated with Cerrado plants. The moth species of this study belongs to the subfamily Stenomatinae that includes 30 genera, and about 1200 species distributed mainly in the Neotropical region (Hodges 1999). In the recent classification by Hodges (1999), Stenomatinae (formerly placed in Oecophoridae) was included in a revised and much expanded concept of Elachistidae. Therefore, the position of the subfamily Stenomatinae is not stabilized yet. The genus Gonioterma Walsingham (1897) contains 33 species, all restricted to the tropical America, nine of them having Brazil as type locality (Heppner 1984). Diniz et al. (2001) reported that three species of Gonioterma were collected in the Distrito Federal: G. exquisita Duckworth, 1964, G. ignobilis Zeller, 1854, and G. indecora Zeller, 1854.

There has been five reports of Gonioterma exquisita, object of the present work, that constitutes its description (Duckworth 1964), bionomic data (Travassos-Filho 1972), some ecological and dietary aspects of its caterpillars (Andrade et al. 1999), and the occurrence and its host plants in the Distrito Federal Cerrado (Diniz et al. 2000; Diniz et al. 2001). Few micromoth species had such a complete adult description as G. exquisita. Despite the mentioned works, most of the biological aspects of this species remained unknown, specially those related to immature stages. It is worthy to note that in the introduction of Duckworth's work (1964), he mentioned that the description of the new species was made in order to allow the publishing of some data of Travassos-Filho in the São Paulo Cerrado, which occurred eight years later in 1972. The immature stages of G. exquisita are restricted to host plants of the genus Byrsonima Rich. (Malpighiaceae) in the Brasília Cerrado (Andrade et al. 1999; Diniz et al. 2000) and in the São Paulo Cerrado (Travassos-Filho 1972). However, it shows a distinct preference for pubescent-leaved plant species (Diniz et al. 2000). The present work enhances the initial efforts of all these authors with the natural history, behavior and description of immatures of G. exquisita.

\section{MATERIALAND METHODS}

The description of immature stages was based on specimens reared in laboratory, and data of natural history and behavior were observed both in laboratory and in the field on its host plant, Byrsonima pachyphylla Griseb (Malpighiaceae), a very common species in the cerrado sensu 
stricto in Brasília. The study site was located at Fazenda Experimental da Universidade de Brasília (Fazenda Água Limpa - FAL, $15^{\circ} 55^{\prime} \mathrm{S}, 47^{\circ} 55^{\prime} \mathrm{W}$ ) in an area of cerrado sensu stricto (Goodland 1971), at 1,100 $\mathrm{m}$ in elevation. This region has two well defined seasons, a dry one from May to September, and a wet one from October to April.

The study was conducted from December 2001 to December 2002. Monthly we inspected 200 plants of $B$. pachyphylla, varying from 0.5 to $2 \mathrm{~m}$ in height and there was no repetition of individuals over the sampling period. All plants were carefully examined searching for G. exquisita caterpillars, and their numbers and sizes were recorded for each individual host. The shelters observed hanging from the host plant with insect jaw marks were used as indicative of predation. The species was identified by Vitor O. Becker. Voucher specimens are deposited in the Coleção Entomológica do Departamento de Zoologia da Universidade de Brasília, Brasília, DF.

The relative size of caterpillars in the field was infered based on the shelter cover diameter and classified into three categories: small - S (1 cm or less); medium - M (from 1.1 to 2 $\mathrm{cm}$ ) and large - L (up to $2 \mathrm{~cm}$ ). To follow the development of $G$. exquisita in the field, six B. pachyphylla plants were marked and 30 small caterpillars were protected by tulle cages. Weekly, from February to December 2002, the size, number, and activity of caterpillars were registered until the emergence of adults.

Between February and March 2002, 20 small and 44 large caterpillars were collected for individual rearing in laboratory. After pupation, the pupae were separated by sex. After the emergence of adults, three pairs of them were placed into plastic vials $(500 \mathrm{ml})$ with fresh $B$. pachyphylla leaves. The leaves were replaced every day, to observe the reproductive cycle and behavior, as well as to describe the eggs and immatures.

To maintain and regulate humidity the immatures were individually reared in plastic vials, on fresh host leaves, which were replaced twice a week. The plastic vials were cleaned daily and sterilized with $70 \%$ alcohol solution. The rearing vials were kept in high humidity and out of direct light exposure. The measurements of larval body and head capsule (HC) size were made using Leica CLS magnifie 150X Heerbrugg (Switzerland) and Olympus CX40 microscope (Japan) with micrometric ocular. Each of these measurements was taken from 20 caterpillars. The HCs from first to seventh instars were collected from lab rearing and the eighth instar HCs was obtained by decapitating the post diapause dead caterpillars (within the 44 large collected in the field). The duration of each stage from egg to the emergence of adults was registered. The results are presented as mean and standard deviation (SD).

In order to assess where the pupation occurs and to follow the last instar caterpillars deaths, 10 nylon nets were set up below 10 host plants containing 42 large or medium caterpillars. These nets were observed weekly during March and April 2002, the active caterpillars were counted and those wich fell into the net were collected and observed in the laboratory.

In the beginning of July 2002, five pairs of pupae were placed in five nylon rearing cages on B. pachyphylla plants free of caterpillars. The aims of this experiment were assessing the viability of the pupae and their reproductive behavior in semi-natural conditions, as well as the adults' survival time. Fifteen field observations were made from the emergence to the adults' death. Seven complementary observations were added totaling 22 observations.

\section{RESULTS}

Description of immature stages:

Eggs: were observed from the first night of adults emergence ( $n=476 ; 158.67 \pm 47.88 /$ female) (Tab. I). They were individually laid dispersed on the abaxial surface of the leaves of B. pachyphylla, camouflaged among trichomes of the same color. The eggs were pale greenish-yellow and elongated (Fig. 1.A), chorion reticulated (Fig. 1.B), slender, and translucid, making possible the observation of the caterpillars embryonic development. From the tenth day, it was possible to see the caterpillars stemata (Fig. 1.A). The embryonic development observed in the laboratory without controlled temperature and humidity conditions, lasted 12 days $(n=268)$. The chorion is the first feeding source to the hatching caterpillars.

Caterpillars. The larval development of $G$. exquisita presented eight instars (Fig. 1.C), seldom recognizable under field conditions due to its cryptic appearence and behavior.

First instar. Head pale yellow $(0.27 \pm 0.03 \mathrm{~mm}$ wide $)$, body integument pale greenish-yellow $(0.97 \pm 0.07 \mathrm{~mm}$ length). Between 24 and 72 hours from egg hatching, the caterpillars began shelter building. The shelters built from frass carefully agregated by silk, covered by a silk-and-trichomes layer, are innitially fixed in the leaf surface, and open at both ends. Duration: 5 to 8 days.

Second instar. Body integument as in the previous instar. Head (0.44 $\pm 0.03 \mathrm{~mm}$ wide), protoraxic shield, annal platte, and pinacula clear chestnut. Shelter now is slightly curved with just one functional openning, carried by the larva. Duration: 13 to 16 days.

Third instar. Body integument as in the previous instar, head $(0.53 \pm 0.05 \mathrm{~mm}$ wide $)$ dark chestnut. Shelter assumes a spiral shape. Duration: 8 to 13 days.

Fourth instar. Body integument with brown protoraxic shield and pinacula, head $(0.69 \pm 0.07 \mathrm{~mm}$ wide $)$ dark chestnut. The shelter presents the definitive spiral shape. Duration: 4 to 11 days.

Fifth instar. Body integument, head $(0.91 \pm 0.06 \mathrm{~mm}$ wide), and shelter as in the previous instar. Duration: 6 to 15 days.

Sixth instar. Body integument, head (1.20 $\pm 0.06 \mathrm{~mm}$ wide), and shelter as in the fourth instar. Duration: 7 to 13 days.

Seventh instar. Body integument, head $(1.70 \pm 0.10 \mathrm{~mm}$ wide), and shelter as in the fourth instar. Duration: 10 to 19 days.

Eighth instar. Protoraxic shield redish-chestnut with black distal edge. Body integument, head, and shelter as in the 
previous instars (Fig. 1.D). Body reaching $18.93 \pm 2.15 \mathrm{~mm}$ length, and head capsule $2.16 \pm 0.19 \mathrm{~mm}$ wide. Duration: 16 to 32 days.

Pupae. the pupa of G. exquisita (Fig. 1.E) is obtect and remains within the shelter, frontally curved. It presents podothecs and pterothecs adhered to the body and covered by the external integument. The integument is transparent, pale yellow in the first day which becomes progressively dark, being redish-chestnut at the eve of emergence, making possible the observation of some details like scales ordering of the wings in the last days of pupa. The proboscid is very developed and the antennae follow all forewing costa vein. The abdominal segments (A5-7) present condyles that permit movement when touched. The last abdominal segment forms the cremaster consisting of a tactil structure with eight capitate setae. Female pupae were heavier and bigger than male pupae. The average duration of the pupa stage is $16.65 \pm 2.05$ days ( $\mathrm{n}=109$; range 13-22).

Adults. A complete description of the adults (Fig. 1.F) can be found in Duckworth (1964), including several figures and comments about the genitalia of G. exquisita and how to distinguish this species from among some of its congenerics.

Shelter. The caterpillars are solitaries and build a hard individual shelter made from silk and frass, covered with trichomes and silk, where they remain until the adult emergence. Shelter's shape varies according to larval instar, but the final shape is like a planorbid shell (Fig. 1.D). The only openning of the shelter may be oriented to the right or to the left, according to the $2^{\text {nd }}$ instar caterpillars source feeding. The larva of $G$. exquisita is relatively sedentary and always moves dragging the shelter, except during the first instar. At the $8^{\text {th }}$ instar the layer of trichomes and silk is discarded, and the larva moves with a partial or totally exposed shelter. This behavior allows some changes in shelter hardness and color, passing from light gray to dark chestnut (Fig. 1.G).
Field observations. Overall we examined 2400 plants, 461 (19.21\%) of which presented 2504 caterpillars (1744 live and 760 dead) of G. exquisita. The number of live caterpillars increased sharply in January and remained high until March 2002 during the second half of the wet season and then declined (Tab.II).

Of the 42 caterpillars, 25 which fell in the interceptation net and was collected (12 dead and 13 in diapause) (Tab. III). From the 17 remaining caterpillars, seven presented parasitism signs, five desappeared, two fell in the herbaceous stratum, one was predated, one died of unknown causes and one was an empty shelter.

Among the 30 caterpillars protected by tulle cages, 16 small caterpillars died before the beginning of March, two medium by the end of March, and three large by the middle of April. The surviving caterpillars $(n=9)$ entered into diapause, from the end of April to the end of November, when they pupated. After the diapause period (about 7 months), the caterpillars did not return to feed. The adults $(n=7)$ emerged between December $2^{\text {nd }}$ and $20^{\text {th }}$.

In the nylon cages experiment, all pupae transported to the field were feasible and reproduced (Tab. I). The average lifetime of the adults differed between those kept in laboratory and those kept in the cages $(t=4.5184 ; \mathrm{p}<0.0005)$. The egg average number oviposited in laboratory was greater than that in the field cages, as well as the number of hatching eggs. No caterpillars born in the field cages reached the $3^{\text {rd }}$ instar, whereas almost half of those born in laboratory pupated and about $90 \%$ of them emerged (Tab. I).

Natural history and behavior.

Feeding. G. exquisita feeds externally only on mature leaves of pubescent Byrsonima species. The first instar larva moves among leaf trichomes, shaves its abaxial surface, and forms little corridors adjacents to the shelter. From the $2^{\text {nd }}$ or $3^{\text {rd }}$ instar, the feeding begins with the shaving of a circular area, and the scraping of a circle around the shaving area. The delimited

Table I. Aspects of the life cycle of G. exquisita in laboratory and in field (cage experiment). SD = Standard deviation.

\begin{tabular}{|c|c|c|c|c|c|c|c|}
\hline \multirow{2}{*}{ Identification } & \multicolumn{2}{|c|}{ Adult lifetime (days) } & \multirow{2}{*}{$\mathrm{N}^{\circ}$ of eggs } & \multirow{2}{*}{$\mathrm{N}^{\circ}$ of hatched eggs } & \multirow{2}{*}{$\begin{array}{l}\text { Feasibility until } \\
\text { pupa stage }(\%)\end{array}$} & \multirow{2}{*}{$\begin{array}{c}\text { Pupae feasibility } \\
(\%)\end{array}$} & \multirow{2}{*}{$\begin{array}{l}\mathrm{N}^{\circ} \text { of } \\
\text { adults }\end{array}$} \\
\hline & $0^{x}$ & 우 & & & & & \\
\hline Lab. 01 & 4 & 8 & 174 & 87 & 55 & 81 & 39 \\
\hline Lab. 02 & 9 & 7 & 197 & 108 & 40 & 95 & 41 \\
\hline Lab. 03 & 5 & 8 & 105 & 73 & 44 & 91 & 29 \\
\hline Mean & 6 & 7.67 & 158.67 & 89.33 & 46.33 & 89 & 36.33 \\
\hline $\mathrm{SD}$ & \pm 2.65 & \pm 0.58 & \pm 47.88 & \pm 17.61 & \pm 7.77 & \pm 7.21 & \pm 6.42 \\
\hline Cage 01 & 10 & 11 & 44 & 25 & 0 & 0 & 0 \\
\hline Cage 02 & 16 & 22 & 77 & 31 & 0 & 0 & 0 \\
\hline Cage 03 & 21 & 17 & 65 & 40 & 0 & 0 & 0 \\
\hline Cage 04 & 10 & 15 & 17 & 11 & 0 & 0 & 0 \\
\hline Cage 05 & 15 & 14 & 22 & 07 & 0 & 0 & 0 \\
\hline Mean & 14.4 & 15.8 & 45 & 22.8 & 0 & 0 & 0 \\
\hline $\mathrm{SD}$ & \pm 4.62 & \pm 4.09 & \pm 26.16 & \pm 13.76 & 0 & 0 & 0 \\
\hline
\end{tabular}



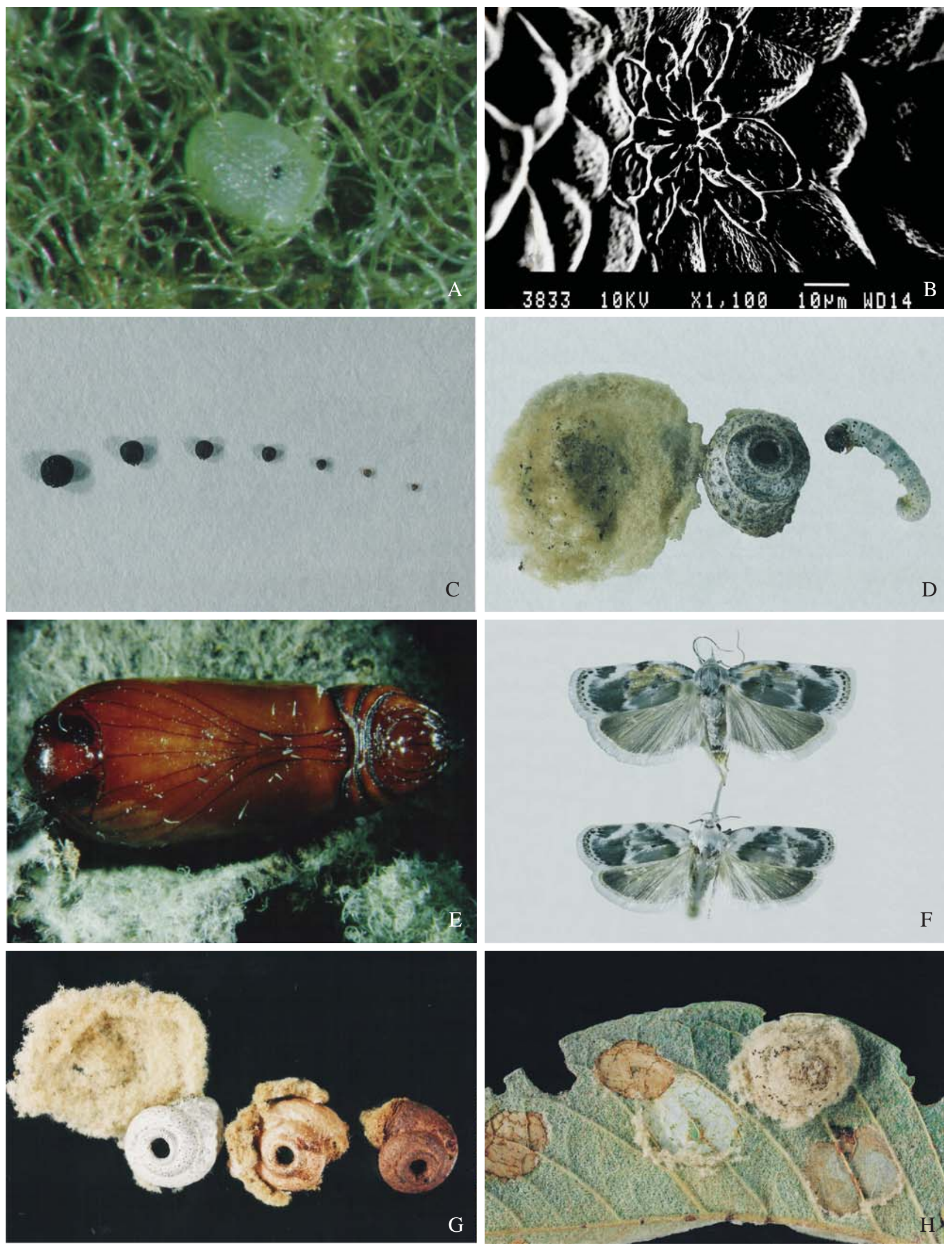

Fig. 1. Aspects of the life cycle of G. exquisita. A, egg in the eve of the hatching; B, egg ultra-struture focusing the micropile; C, Head capsules from $2^{\text {nd }}$ to $8^{\text {th }}$ instars; D, A $8^{\text {th }}$ instar caterpillar with shelter, and trichomes and silk layer; E, pupa; F, adults $q$ and $\sigma^{*}$ from up to down; G, shelters progressive darkening; and $\mathrm{H}$, feeding caterpillar signs and its characteristic leaf damage. 
Table II. Abundance and mortality of G. exquisita in B. pachyphylla. Small (S), medium (M), and large (L) caterpillars.

\begin{tabular}{|c|c|c|c|c|c|c|}
\hline \multirow{3}{*}{ Month } & \multicolumn{6}{|c|}{ Number and size of the caterpillars } \\
\hline & \multicolumn{3}{|c|}{ live } & \multicolumn{3}{|c|}{ dead } \\
\hline & $\mathrm{S}$ & $\mathrm{M}$ & $\mathrm{L}$ & S & $\mathrm{M}$ & $\mathrm{L}$ \\
\hline December & 07 & 0 & 0 & 0 & 0 & 0 \\
\hline January & 488 & 0 & 0 & 0 & 0 & 0 \\
\hline February & 486 & 200 & 30 & 0 & 0 & 0 \\
\hline March & 24 & 146 & 175 & 164 & 10 & 02 \\
\hline April & 11 & 09 & 39 & 61 & 12 & 13 \\
\hline May & 53 & 02 & 07 & 98 & 44 & 27 \\
\hline June & 29 & 08 & 05 & 106 & 34 & 27 \\
\hline July & 09 & 09 & 07 & 72 & 34 & 03 \\
\hline Agost & 0 & 0 & 0 & 27 & 13 & 02 \\
\hline September & 0 & 0 & 0 & 05 & 03 & 03 \\
\hline Total & 1107 & 374 & 263 & 533 & 150 & 77 \\
\hline
\end{tabular}

area is scraped from the abaxial surface to the mesophyl, but the adaxial epiderm and some leaf veins remain intact. This behavior results in a very characterist semi-transparent damage pattern (Fig. 1.H). The trichomes are heaped up with silk as a layer covering over the shelter, forming a trichome continual with the leaf.

Parasitoids and predators. Caterpillars of all sizes and pupae were sponged (Tab. III). Among the parasitoids, 10 morphospecies of four Hymenoptera families were found: Braconidae (seven), Eulophidae (one), Eupelmidae (one) and Perilampidae (one - hiperparasitoid). The parasitoids were sent to a specialist to identification. There was also a dipteran parasitoid of the Tachinidae family. Four caterpillars of $G$. exquisita were sponged by juvenil nematoids Hexamermis sp. (Nemata: Mermithidae). Although the predators were not seen, its peak occurred between the end of April to the beginning of May, and it was directed toward to the last instar caterpillars.

Ecdisis and pupating. The ecdisis is preceded by sticking the shelter with a silk bunch to the leaf vein. This process can last for one to three days. All the HCs are released frontally and intact, but the last one remains within the shelter. After the caterpillars stop feeding, they leave the host plant and fall in the herbacious stratum, where they stick their shelter to a leaf or stem of any plant species. The caterpillars make a weak silk fencing in the shelter opennig, and then may enter in diapause or pupate. At the pupation occasion, the $\mathrm{HC}$ opens in the ecdisial line and it glides with the remaining exuvia over the pupa integument. It is the only oportunity to collect the complete exuvia.

Emergence. As the adults emerge, they stretch their wings and keep them in a veliform position (the wings sticked together over the back). The resting position is tectiform with alternate overlapping of forewings. The emergence was observed between 06:00 p.m. to 06:00 a.m. $(n=78)$. The reproduction observations in laboratory showed that the females emerge with eggs ready to be fertilized.

\section{DISCUSSION}

Caterpillars of tropical Lepidoptera are poorly known, and unless reared to adults, they are virtually impossible to identify specifically (Pogue \& Aiello 1999). The situation becomes worse in case of natural history and immature stages of Stenomatinae (Elachistidae). Consequently, the descriptions of the several instars, pupa and behavior will be a worthy subsidy to provide basic information, extremely needed for almost all Lepidoptera.

There are some indications that G. exquisita is multivoltine. Field observations confirm several instars of active caterpillars from December to July, even tough there is progressive reduction in number, which could be attributed to delay in oviposition or even to differences in individual development. The first caterpillars found in the field may be originated from the females that passed diapause as caterpillars from April to November.

Among the large caterpillars collected in the field, there was the same proportion of diapause and no diapause individuals, which suggests a facultative diapause. The adults resulting from tulle bags protected caterpillars, were appearently vigorous and they did not seem to lose weight across the diapause. No laboratory larva entered in diapause. It may be explained by the low oscillations in humidity and temperature conditions in the laboratory.

Table III. Mortality, caterpillars diapause, and adult emergence of G. exquisita. Small (S), and large (L) caterpillars ( $\mathrm{n}^{\circ}$ of adults).

\begin{tabular}{|c|c|c|c|c|c|c|c|}
\hline \multirow{2}{*}{ Site and initial number } & \multicolumn{5}{|c|}{ Missing causes } & \multicolumn{2}{|c|}{ Final } \\
\hline & Sponged by insects & Predated & Nematoids & Fungus & Unknown & Diapause & No Diapause \\
\hline \multicolumn{8}{|l|}{ In the field } \\
\hline Intercepting net $25 \mathrm{~L}$ & 07 & 0 & 0 & 05 & 0 & $13(0)$ & 0 \\
\hline Tulle cages $30 \mathrm{~S}$ & 0 & 01 & 01 & 0 & 19 & $09(07)$ & 0 \\
\hline \multicolumn{8}{|l|}{ In the laboratory } \\
\hline Collect from field $44 \mathrm{~L}$ & $09 *$ & 0 & 02 & 06 & 01 & $13(0)$ & $13(13)$ \\
\hline Collect from field $20 \mathrm{~S}$ & 08 & 0 & 01 & 02 & 05 & $02(0)$ & $02(02)$ \\
\hline Lab. rearing $20 \mathrm{~S}$ & 0 & 0 & 0 & 0 & 04 & 0 & $16(16)$ \\
\hline
\end{tabular}

* There was a pupa among them. 
There are several reports in the literature about lepidopteran species that present facultative diapause. In spite of this, this subject is poorly investigated in the cerrado region. Trudel et al. (1999) verified that under favourable conditions, Dioryctia abietivorella (Pyralidae) can develop from egg to adult without entering in diapause but in the field it diapauses during the winter. These autors suggested that the diapause is facultative to this species and that some enviromental conditions like host plant quality may induce diapause. Scoble (1992) cites Agrotis infusa (Noctuidae), an Australlian moth, in which most of the individuals migrate from the plains to the mountains where they aestive and the remaining individuals enter in diapause. This autor states that both migration and facultative diapause are escape strategies from conditions that induce egg maturation, to avoid limited food resources to the caterpillars. According to Kfir et al. (2002) a delay in the humidity increasing after the diapause as well as an early water access may have deleterious effect to the caterpillars.

There are notorious advantages to G. exquisita in passing the diapause as $8^{\text {th }}$ instar larva: (1) being within a mechanically hard shelter, cryptic in color that has random location in the plants of the herbacious stratum; (2) escaping from stressing abiotic conditions (dry season in cerrado lasts for five months); (3) maximising fitness by waiting for higher leaf nutritional quality for the offspring, reducing the residence time in the host plant, escaping from natural enemies, and increasing the biomass and vigour of the adults. In the case of G. exquisita, the diapause can be an efficient way to guarantee higher quality food availability to the caterpillars, since the host plant is deciduous and the caterpillars have low mobility. This acts as an adjustment factor between its life cycle and the leaf phenology of $B$. pachyphylla. The highest production of leaves of $B$. pachyphylla in the cerrado occurs during September to November (across the transition of dry to wet seasons). At the emergence of adults from diapause, the host plants present mature leaves younger than those available during the dry season.

Travassos-Filho (1972) working in the São Paulo cerrado, found three parasitoid species for G. exquisita: a Braconidae and an Ichneumonidae (Hymenoptera), and a Sarcophagidae (Diptera). On the other hand, the Brasília cerrado presents a high parasitoid species diversity expressed in ten hymenopteran and one dipteran species, besides a nematoid parasite. Such results suggest that, despite all combined cryptic strategies and behaviors, this moth undergoes a very diverse parasitoid pressure.

Zalucki et al. (2002), based on a vast literature about Lepidoptera, pointed out a high mortality in initial instars (between 9 and 96\%), normally with missing levels between $25-75 \%$ ( 80 species). These autors highlighted that approximately $41 \%$ of the eggs and $54 \%$ of first instar caterpillars are lost, resulting in the survival of just 27 out 100 initial eggs until the end of the first instar. Confronting this information with the observed survival rate in G. exquisita, the total number of hatched eggs both in the field and laboratory is close to this projection. The restricted diet and the scattered oviposition may favor the survival of G. exquisita. Lepidopterans of diet restricted to a family host plant present a mortality rate of about $43 \%$ in initial instars (compared to $57 \%$ among those of generalist diet), and the species that oviposite in clusters have a mortality rate of about $60 \%$ in the first instar (Zalucki et al. 2002). Despite the relatively high numbers of eggs/female ( $158.67 \pm 47.88$ eggs), the fecundity is certainly underestimated. The bucal apparatus of adult $G$. exquisita is functional, being possible that the adult feeding may increment the longevity and therefore the reproductive output.

When disturbed, the larva enters the shelter moving almost $1 \mathrm{~cm}$ from its opening. This behavior is compatible with the marks of predation found in some shelters since the predator cuts the shelter at this point, making difficult the escape of the larva. The shelter becomes soft and cutting easy when wet, which could explain the peak of predation at the end of the wet season. The predation was directed towards the last instar caterpillars possibly due to their conspicuous appearence in the host plant after losing the trichomes layer that covered the shelter.

As regards laboratory rearing, theoretically it is possible to keep caterpillars of G. exquisita all year long. The food source, however, decreases its nutritional quality as the leaves age, influencing the larval stage duration. The females seem to have a foresight about food source availability to the caterpillars (low mobility), which might explain the oviposition differences between females in the field and in the laboratory. On the other hand, the stress of being in a small vial could induce the females to oviposite. The lifetime was greater in the field than in the laboratory, suggesting that the adults can overpass the unfavourable conditions better than the caterpillars.

The pupation occurs out of the host plant and this is indicated by the trichome layer discarding behavior. It makes the shelter cryptic after its fall in the herbaceous stratum. Pupating out of the host plant is a common behavior among lepidopterans and can lead collectors to mistaken conclusions. It is worthy to remember that the presence of a pupa does not indicate that the larva consumed the plant where it was found except when the diet range of its immatures is known.

Acknowledgements. We would like to thank Dr. Vitor O. Becker, who identified the moth. Dr. Juvenil Cares (Universidade de Brasília), for the nematoid identification. Dr. Sônia Báo for electronic microscope pictures (Universidade de Brasília). Dr. Helena C. Morais (Universidade de Brasília) for her valuable comments and Dr. Mundayatan Haridasan (Universidade de Brasília) who made suggestions and corrections in the manuscript. $\mathrm{CNPq}$ provided a scholarship for the first autor.

\section{REFERENCES}

Andrade, I.; H. C. Morais; I. R. Diniz \& C. Van den Berg. 1999. Richness and abundance of caterpillars on Byrsonima (Malpighiaceae) species in an area of cerrado vegetation in Central Brazil. Revista de Biología Tropical 47: 691-695.

Diniz, I. R.; H. C. Morais \& J. D. Hay. 2000. Natural history of 
herbivores feeding on Byrsonima species. Brazilian Journal of Ecology 1 and 2: 49-54.

Diniz, I. R.; H. C. Morais \& A. J. A. Camargo. 2001. Host plants of lepidopteran caterpillars in the cerrado of the Distrito Federal, Brazil. Revista Brasileira de Entomologia 45: 107-122.

Duckworth, W. D. 1964. A new Brazilian moth of the genus Gonioterma with notes on related species (Lepidoptera: Stenomidae). Proceedings of the United States National Museum 115: 381-390.

Goodland, R. 1971. A physionomic analysis of the "cerrado" vegetation of central Brazil. Journal of Ecology 59: 411-419.

Heppner, J. B. 1984. Atlas of Neotropical Lepidoptera checklist, Micropterigoidea-Immoidea Part.I ed. W. Gunk Publishers. 112 p.

Hodges, R. W. 1999. The Gelechioidea. p 132-158. In: N. P. Kristensen (ed.). Lepidoptera, moths and butterflies. Vol. 1: Evolution, Systematics and Biogeography. Berlin \& New York, Walter de Guvter. vii... + xxx p.
Kfir, R.; W. A. Overholt; Z. R. Khan \& A. Polaszek. 2002. Biology and management of economically important lepidopteran cereal stem borers in Africa. Annual Review of Entomology 47: 701-31.

Pogue, M. G. \& A. Aiello. 1999. Description of the immature stages of three species of Eulepidotis Guenée (Lepidoptera: Noctuidae) with notes on their natural history. Proceedings of the Entomological Society of Washington 101: 300-311.

Scoble, M. J. 1992. The Lepidoptera: form, function and diversity. Oxford University Press. 404 p.

Travassos-Filho, L. P. 1972. Dados bionômicos de Gonioterma chlorina e de G. exquisita (Lepidoptera, Stenomidae). Studia Entomologica 15: 485-496.

Trudel, R.; E. Bauce; C. Guertin \& J. Cabana. 1999. Diapause induction and overwintering stage in the fir coneworm (Lepidoptera: Pyralidae). The Canadian Entomologist 131: 779-786.

Zalucki, M. P.; A. R. Clarke \& S. B. Malcolm. 2002. Ecology and behavior of first instar larval Lepidoptera. Annual Review of Entomology 47: 361-93. 